Koedoe 14: 123-129 (1971).

\title{
BIRD SPECIES DENSITY IN THE KALAHARI AND THE AUSTRALIAN DESERTS
}

by

\author{
ERIC R. PIANKA* and RAYMOND B. HUEY*
}

\section{Introduction: Study Areas and Methods}

During a year-long field study centering on the ecology and species diversity of Kalahari desert lizards (Pianka, in press), supporting observations were made on the avifauna. Here we report on and discuss these results; in addition, some comparisons are made with Australian desert birds, using data of Pianka and Pianka (1970).

Nine study areas were selected (Table 1), varying in physiography, topography, climate, and vegetative structure. Areas were chosen along a rainfall gradient in order to test the effect of rainfall and productivity (see Walter, 1939) on the number of species of birds. The easternmost four areas $(\mathrm{G}, \mathrm{D}, \mathrm{R}$, and $\mathrm{T})$ have an average annual rainfall of over $200 \mathrm{~mm}$, whereas the five more westerly areas have a long-term mean annual precipitation of less than $200 \mathrm{~mm}$. The latter five sites (L, K, B, A, and X all lie within the "dune area" of the southern Kalahari as delineated by Leistner (1967). Areas A, X, L, and K are crossed by long dunes, characteristic of the eastern part of the southern Kalahari. On area B, dunes are quite far apart and the resulting troughs are extensive, sometimes up to 2 to $4 \mathrm{~km}$ wide. Area $\mathrm{G}$ is a flatland shrub desert, with a vegetation consisting predominantly of small chenopodeaceous perennials. Area $\mathrm{R}$ is a nearly "pure" Rhigozum site; area D, on fairly flat terrain, supports a mixture of small to large shrubs, including Acacia mellifera and Grewia flava. Area T, about $11 \mathrm{~km}$ south of Tsabong, Botswana, is an open forestsavanna area with a fair number of trees.

The dune area of the southern Kalahari, also called the "sandveld" or the "duneveld", supports a vegetation composed largely of various perennial grasses such as Stipagrostis amabilis (on dune crests), S. ciliata, S. obtusa, $S$. uniplumis, Asthenatherum glaucum and Eragrostis lehmanniana. Rhigozum trichotomum and Grezicia flava ar common woody shrubs. Various small acacias, such as Acacia mellifera and $A$. hematoxylon, are widespread. Small trees, especially Acacia giraffae and Boscia albitrunca, are scattered throughout the region, being common enough in some areas to suggest a savannalike vegetation. Detailed descriptions of the vegetation, with photographs, may be found in Leistner (1967).

*Department of Zoology, University of Texas at Austin, Austin, Texas 78712, U.S.A. 
At least 32 large quadrats ( 58 to $232 \mathrm{~m}^{2}$ ) were staked out on each study area, and all perennial plants within these quadrats were identified, measured and counted. Linear measurements of the height and width of shrubs and trees were made and used to estimate plant volumes, using formulae for the volumes of oblate and prolate spheroids, respectively, depending upon the general shape of each shrub and tree. The area covered by a plant was estimated using its width and the formula for the area of a circle. (No allowance was made for foliage density differences between plants.) Such values for individual perennial were then used to compute a variety of vegetational statistics including percentage coverage and the volume of plants per quadrat. Plant species diversity was calculated using Shannon's (1949) information theoretical index, $\mathrm{H}=-\sum \mathrm{p}_{\mathrm{i}} \ln \mathrm{p}_{\mathrm{i}}$, where $p_{i}$ is the proportion of the total volume belonging to plant species $i$. The same formula was used to calculate plant height diversity using as $\mathrm{p}_{\mathrm{i}}$ 's the proportion of plants over $2 \mathrm{dcm}$ belonging to three height categories (3-6, 7-14, and over $15 \mathrm{dcm})$. Standard symbols are used for the mean $(X)$, standard deviation $(S)$, sample size $(\mathcal{N})$, and correlation coefficient $(r)$.

\section{Results and Discussion}

Appendix I lists the bird species known to occur on each of the study areas. Most of the birds were identified during late fall and early spring (May to October 1970). From 16 to 41 species of birds occur in ecological sympatry on the various sites. The majority of species are classified as "residents" of the southern Kalahari by Maclean (1970). Appendix I also lists the probable foraging niche and food niche for each of the species concerned; these data are discussed later in the comparison with Australian desert birds.

Using Shannon's equation, MacArthur and MacArthur (1961), Recher (1969) and Cody (1970) demonstrated that "bird species diversity" is strongly correlated with "foliage height diversity". We therefore anticipated that the vertical structure of the vegetation would exert a strong influence on the numbers of bird species. Frequency distributions of perennial plant heights are listed in Table 2 for each of the study areas. Because of the large numbers of very small plants, and because these tiny perennials are seldom directly used by birds, we omitted all plants under $2 \mathrm{dcm}$ in height from consideration in calculating "plant height diversities".

First, we simply examined five variables (Table 3 ) for correlations with bird species density. Of these, only plant height diversity was significantly correlated with bird species density $(r=0,795, \mathrm{P}<0,01)$. We plot this correlation in Figure 1.

Using multiple regression, MacArthur and MacArthur (1961) demonstrated that "plant species diversity" did not contribute to predicting "bird species diversity", once "foliage height diversity" was known. We 
ran a stepwise multiple regression analysis on the data of Table 3 with the results summarized in Table 4. Plant height diversity alone accounts for some $63 \%$ of the variation in bird species density $\left(r^{2}=0,63\right)$; addition of the other four variables reduces the unexplained variation by another $21 \%$. All five variables listed in Table 3 therefore "explain" some $85 \%$ of the variance in bird species density.

Using information provided by McLachlan and Liversidge (1957), foraging niches and food niches were assigned to most species (we are also indebted to G. L. Maclean for help with these assignments). [A few poorly known species could not be assigned to a category and are of necessity omitted in what follows.] All birds assigned foraging and food niches were then grouped into the following four categories, making up 2 by 2 contingency tables: (1) ground foraging herbivores, (2) ground foraging carnivores, (3) arboreal herbivores, and (4) arboreal carnivores, including hawking and flying carnivores. A few species had to be assigned to two or four of these categories; they were tallied either as $0,3,0,5$, or 0,7 of a category. Scavengers were classified as carnovires and most omnivores were classified as 0,5 carnivorous and 0,5 herbivorous. The same procedure was followed for birds on eight Australian desert areas (Pianka and Pianka, 1970), using Cayley (1959) and Serventy and Whittell (1967) for information of foraging and food niches (we are indebted to Helen D. Pianka for making these assignments).

Table 5 lists the numbers of species in each category. There is a disproportionate increase in arboreal species as overall bird species density increases in the Kalahari, that is, arboreal birds are added faster than ground birds as species density increases. Several significant interrelated differences between the two continental systems are apparent: (1) there are proportionately more species of ground carnivores in the Kalahari than in Australia, (2) ground herbivore percentages are similar on both continents, and (3) there are proportionately more species of arboreal carnivores (and arboreal species in general) in Australia than there are in the Kalahari.

Thus, these results provide limited evidence of some fundamental differences in avian niches in the Kalahari and the Australian desert.

\section{Acknowledgements}

We gratefully acknowledge C. K. Brain, W. D. Haacke, and G. Newlands of the Transvaal Museum, G. de Graaff of the National Parks Board, R. H. Smithers of the National Museums of Rhodesia and L. D. Tennant of the Botswana Department of Wildlife and National Parks for their assistance throughout our study. We also thank G. L. Maclean and H. D. Pianka for help in assigning bird niches, but hold ourselves responsible for any errors. Finally, we thank L. W. Coons and D. Christie for assistance in the field.

This research was supported by a grant from the U.S. National Science Foundation (no. GB-8727). 


\section{Summary}

From 16 to 41 species of birds occur in sympatry on nine study areas in the southern Kalahari. Nearly $85 \%$ of the variance in bird species density can be accounted for with only five independent variables: mean percent coverage by perennial plants, number of perennial plant species, plant species diversity (by volume), plant height diversity, and long-term average annual precipitation. Some $63 \%$ of the variance in bird species numbers can be attributed to variation in plant height diversity from area to area. Bird species lists are broken down into four simple niche categories (ground herbivores, ground carnivores, arboreal herbivores, and arboreal carnivores), and it is demonstrated that the number of species in all categories increases with increasing plant height diversity. Arboreal species are added faster with increasd plant height diversity than ground, thus rendering the above correlation biologically meaningful. Compared with Australian deserts, the Kalahari supports proportionately more species of ground carnivores, fewer arboreal species, but about the same number of ground herbivore species.

\section{REFERENCES}

CAYLEY, N. W. 1959. What bird is that? 3rd ed. Sydney: Angus and Robertson. CODY, M. L. 1970. Chilean bird distribution. Ecology 51: 455-464.

LEISTNER, O. A. 1967. The plant ecology of the southern Kalahari. Bot. Surv. S. Afr. Mem. 38.

MACARTHUR, R. H. and J. MACARTHUR. 1961. On bird species diversity. Ecology 42: 594-598.

MACLEAN, G. L. 1970. An analysis of the avifauna of the southern Kalahari Gemsbok National Park. Zool. afr. 5: 249-273.

MCLACHLAN, G. R. and R. LIVERSIDGE. 1957. Roberts birds of South Africa. Johannesburg: Central News Agency.

PIANKA, E. R. (in press). Lizard species density in the Kalahari desert. Ecology 52.

PIANKA, H. D. and E. R. PIANKA. 1970. Bird censuses from desert localities in Western Australia. Emu 70: 17-22.

RECHER, H. F. 1969. Bird species diversity and habitat diversity in Australia and North America. Amer. Nat. 103: 75-79.

SERVENTY, D. L. and H. M. WHITTELL. 1967. Birds of Western Australia. 4th ed. Perth: Lamb Publications.

SHANNON, C. E. 1949. The mathematical theory of communication. In: Shannon, C. E., and W. Weaver [eds.] The mathematical theory of communication. Urbana: University of Illinois Press.

WALTER, H. 1939. Grasland, Savanne und Busch der arideren Teile Afrikas in ihrer ökologischen Bedingtheit. Jahrb. Wiss. Bot. 87: 750-860. 


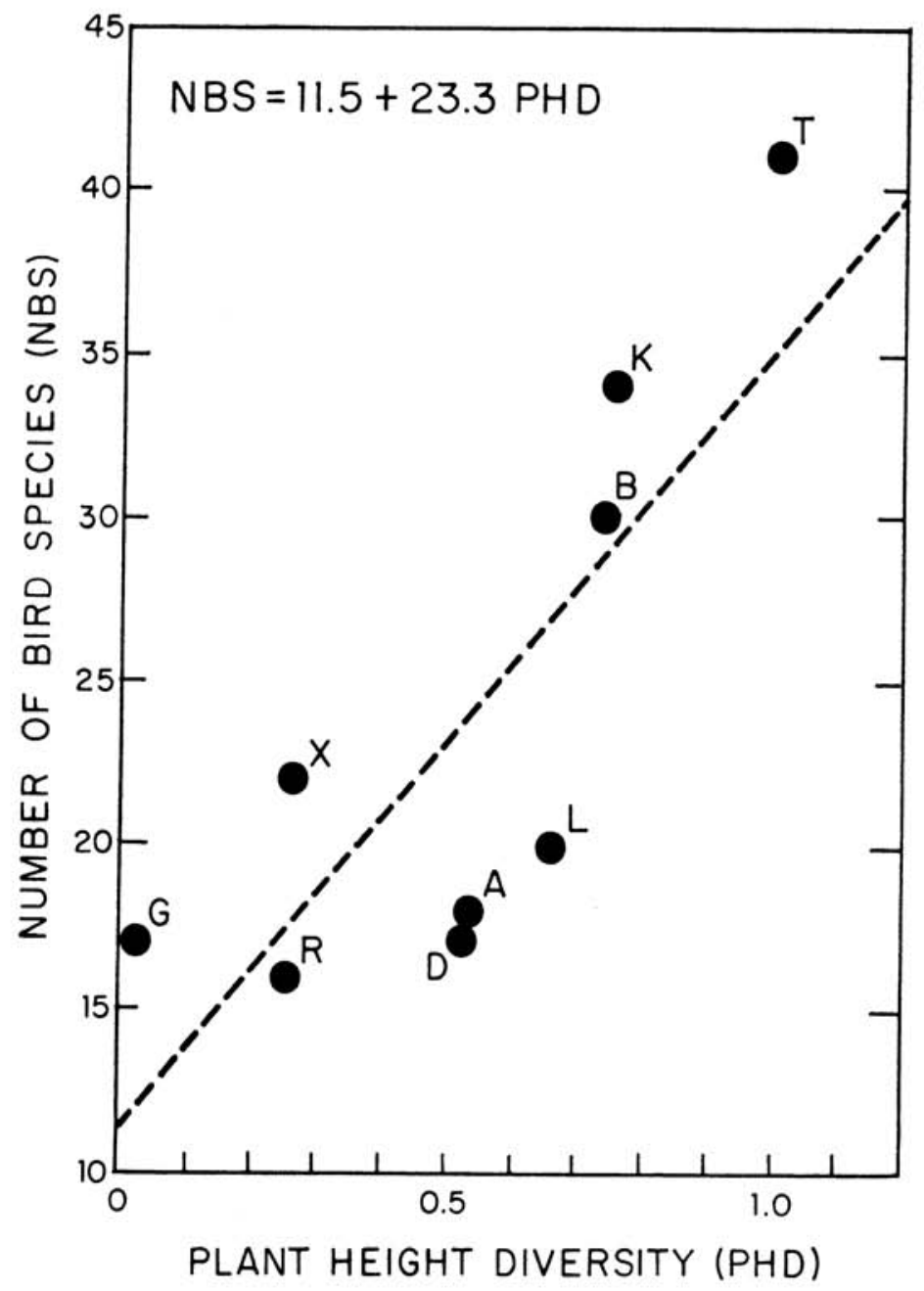

Fig. 1 Plot of bird species density against plant height diversity, with least squares linear regression equation and line. The Pearson product moment correlation coefficient $(0,795)$ is significant at the $99 \%$ level. 
Table 1

Locations of the nine study areas

\begin{tabular}{clcc} 
Area & \multicolumn{1}{c}{ Location } & Lat. ${ }^{\circ} S$ & Long. ${ }^{\circ} \mathrm{E}$ \\
L & $14 \mathrm{~km}$ NE Twee Rivieren, Botswana & $23^{\circ} 26^{\prime}$ & $20^{\circ} 43^{\prime}$ \\
K & $1 \mathrm{~km}$ W Kameel Sleep, R.S.A. & $25^{\circ} 45^{\prime}$ & $20^{\circ} 44^{\prime}$ \\
B & Farm Bloukranz, R.S.A. & $27^{\circ} 00^{\prime}$ & $20^{\circ} 27^{\prime}$ \\
A & Farm Aarpan, R.S.A. & $27^{\circ} 22^{\prime}$ & $20^{\circ} 43^{\prime}$ \\
X & Farm Vrederus, R.S.A. & $27^{\circ} 22^{\prime}$ & $21^{\circ} 25^{\prime}$ \\
G & Farm Geselskop, R.S.A. & $28^{\circ} 13^{\prime}$ & $22^{\circ} 16^{\prime}$ \\
D & Farm Gemsbok, R.S.A. & $27^{\circ} 17^{\prime}$ & $21^{\circ} 54^{\prime}$ \\
R & Farm Miershoopholte, R.S.A. & $28^{\circ} 17^{\prime}$ & $22^{\circ} 05^{\prime}$ \\
T & 11 km S Tsabong, Botswana & $26^{\circ} 08^{\prime}$ & $22^{\circ} 28^{\prime}$
\end{tabular}

Table 2

Frequency distributions (numbers of plants) of height of perennial plants on each of the nine study areas. Height categories in decimeters.

\begin{tabular}{lrrrrrrrrr} 
Height & \multicolumn{1}{c}{$R$} & \multicolumn{1}{c}{$\mathrm{G}$} & \multicolumn{1}{c}{$A$} & \multicolumn{1}{c}{$L$} & \multicolumn{1}{c}{$X$} & \multicolumn{1}{c}{$B$} & \multicolumn{1}{c}{$K$} & $T$ \\
1 & 887 & 1316 & 1261 & 853 & 6069 & 3045 & 4635 & 215 & 85 \\
2 & 465 & 696 & 423 & 55 & 507 & 1885 & 459 & 118 & 78 \\
3 & 346 & 633 & 401 & 99 & 447 & 941 & 156 & 227 & 79 \\
4 & 1403 & 408 & 306 & 451 & 469 & 612 & 76 & 306 & 94 \\
5 & 574 & 136 & 133 & 80 & 306 & 167 & 118 & 158 & 39 \\
6 & 269 & 29 & 63 & 53 & 224 & 28 & 155 & 148 & 27 \\
7 & 133 & 3 & 39 & 43 & 169 & 4 & 167 & 232 & 26 \\
8 & 39 & & 43 & 35 & 103 & 5 & 153 & 220 & 19 \\
9 & 17 & & 24 & 24 & 329 & 7 & 123 & 128 & 15 \\
10 & 13 & & 6 & 29 & 22 & 4 & 105 & 107 & 15 \\
11 & 2 & & 10 & 16 & 19 & 76 & 45 & 70 & 9 \\
12 & 1 & & 25 & 17 & 38 & 17 & 58 & 71 & 12 \\
13 & 1 & & 15 & 19 & 14 & 10 & 8 & 20 & 10 \\
14 & 1 & & 11 & 4 & 2 & 3 & 4 & 10 & 8 \\
$15-20$ & & & 20 & 1 & 10 & 7 & 1 & 13 & 17 \\
$21-25$ & & & & 1 & 3 & 1 & 3 & 4 & 13 \\
$26-30$ & & & 1 & & 1 & & 8 & 1 & 33 \\
$31-35$ & & & & & & & & 1 & 5 \\
$36-40$ & & & & & & & 1 & 1 & 9 \\
$41-45$ & & & & & & & & & 7 \\
$46-50$ & & & & & & & & 4 & 6
\end{tabular}




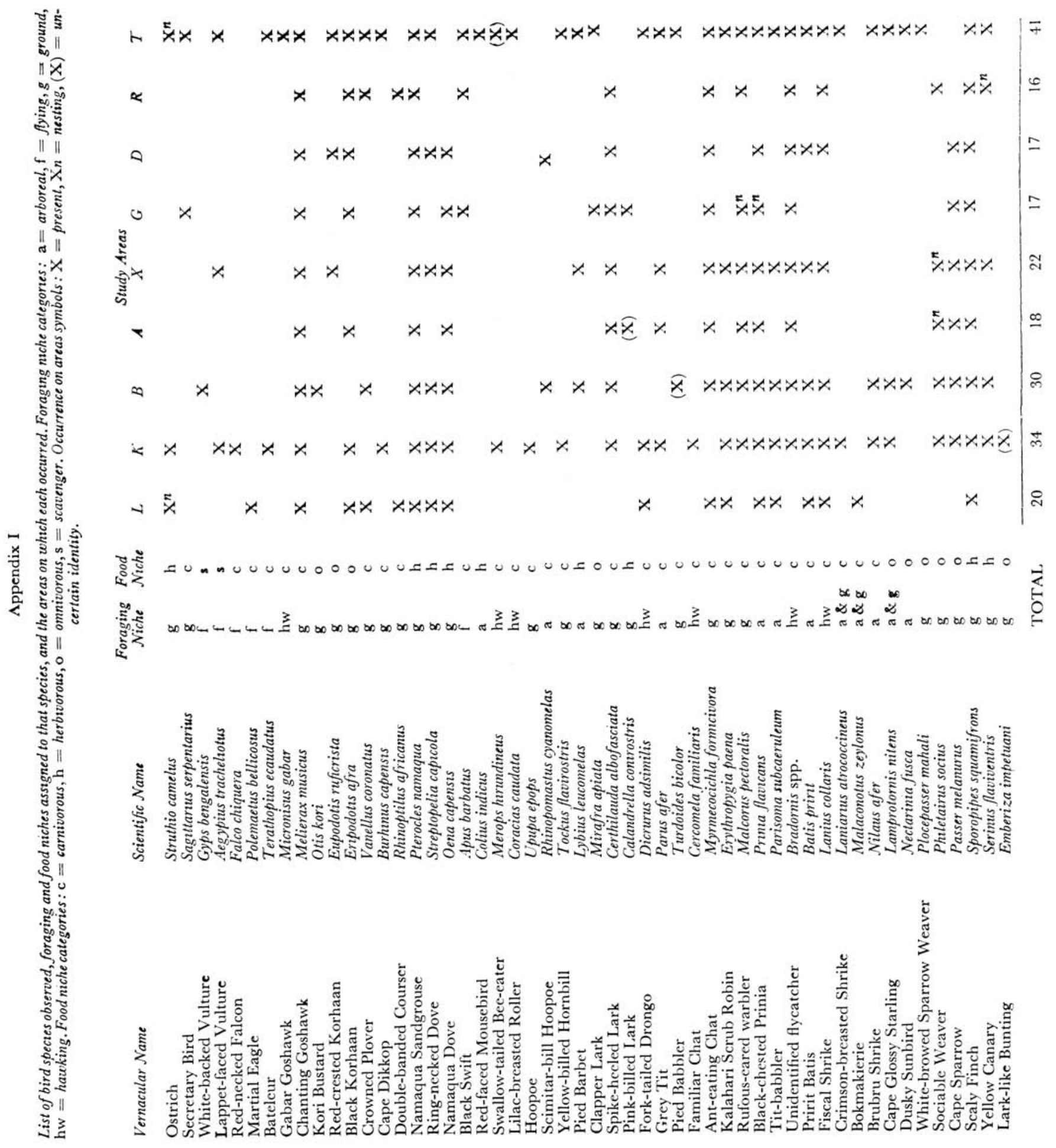


Estimates of the number of bird species (NBS), the mean percentage cover by perennials $(M P C)$, the number of species of perennials (NSP), the long-term average annual precipitation (LTP), plant species diversity weighting each species by its volumetric proportion of the total perennial vegetation $(P S D)$, and plant height diversity as explained in text $(P H D)$.

\begin{tabular}{ccccccc} 
Area & NBS & MPC & NSP & LTP & PSD & PHD \\
$R$ & 16 & 21,3 & 7 & 225 & 0,69 & 0,264 \\
$G$ & 17 & 12,6 & 8 & 227 & 1,11 & 0,019 \\
$D$ & 17 & 7,2 & 17 & 217 & 1,84 & 0,527 \\
$A$ & 18 & 10,7 & 13 & 145 & 1,44 & 0,534 \\
$L$ & 20 & 10,1 & 14 & 167 & 1,86 & 0,667 \\
$X$ & 22 & 8,6 & 10 & 190 & 1,48 & 0,270 \\
$B$ & 30 & 9,4 & 13 & 152 & 1,50 & 0,744 \\
$K$ & 34 & 13,9 & 15 & 190 & 1,46 & 0,757 \\
$T$ & 41 & 18,7 & 16 & 286 & 1,40 & 1,015 \\
\hline$r$ & - & 0,279 & 0,508 & 0,330 & 0,142 & 0,795 \\
\hline
\end{tabular}

Table 4

Results of a stepwise multiple regression on the data of Table 3.

(Symbols as in Table 3.)

The number of bird species is the dependent variable.

$\begin{array}{ccccc}\begin{array}{c}\text { Step } \\ \text { Number }\end{array} & \begin{array}{c}\text { Variable } \\ \text { Entered }\end{array} & r & r^{2} & \begin{array}{c}\text { Increase } \\ \text { in } r^{2}\end{array} \\ 1 & \text { PHD } & 0,795 & 0,633 & 0,633 \\ 2 & \text { LTP } & 0,844 & 0,713 & 0,080 \\ 3 & \text { NSP } & 0,873 & 0,762 & 0,049 \\ 4 & \text { MPC } & 0,899 & 0,809 & 0,047 \\ 5 & \text { PSD } & 0,919 & 0,845 & 0,036\end{array}$


The numbers of species of birds in each of four niche categories are listed for nine Kalahari study areas and for eight structurally similar areas in the Western Australian desert. Percentages are given in parentheses. The rightmost two columns give the overall percentage of carnivorous and arboreal species.

\begin{tabular}{|c|c|c|c|c|c|c|c|}
\hline Area &.$N$ & $\begin{array}{l}\text { Ground } \\
\text { Herbivores }\end{array}$ & $\begin{array}{l}\text { Ground } \\
\text { Carnivores }\end{array}$ & $\begin{array}{l}\text { Arboreal } \\
\text { Herbivores }\end{array}$ & $\begin{array}{c}\text { Arboreal } \\
\text { Carnivores }\end{array}$ & $\begin{array}{c}\text { Per- } \\
\text { centage } \\
\text { Carni- } \\
\text { vorous }\end{array}$ & $\begin{array}{l}\text { Per- } \\
\text { cenlage } \\
\text { Arboreai }\end{array}$ \\
\hline $\mathrm{R}$ & 15 & $4,0(27)$ & $7,0(47)$ & $0,0(0)$ & $4,0(27)$ & $(73,2)$ & $(26,7)$ \\
\hline G & 16 & $5,5(34)$ & $6,5(41)$ & $0,0(0)$ & $4,0(25)$ & $(65,6)$ & $(25,0)$ \\
\hline D & 16 & $5,5(34)$ & $4,5(28)$ & $0,0(0)$ & $6,0(38)$ & $(65,6)$ & $(37,5)$ \\
\hline A & 16 & $5,5(34)$ & $5,5(34)$ & $0,0(0)$ & $5,0(31)$ & $(65,6)$ & $(31,2)$ \\
\hline I. & 19 & $5,5(29)$ & $6,0(32)$ & $0,0(0)$ & $7,5(40)$ & $(71,0)$ & $(39,4)$ \\
\hline $\mathrm{X}$ & 21 & $6,5(31)$ & $6,5(31)$ & $1,0(5)$ & $7,0(33)$ & $(64,3)$ & $(38,1)$ \\
\hline B & 29 & $6,8(23)$ & $8,7(30)$ & $1,8(6)$ & $11,7(40)$ & $(70,7)$ & $(46,6)$ \\
\hline K & 33 & $8,3(25)$ & $9,7(29)$ & $0,3(1)$ & $14,7(45)$ & $(74,2)$ & $(45,4)$ \\
\hline $\mathrm{T}$ & 40 & $7,3(18)$ & $11,7(29)$ & $2,8(7)$ & $18,2(46)$ & $(75,0)$ & $(52,4)$ \\
\hline means & 22,8 & $6,1(28)$ & $7,3(34)$ & $0,7(2)$ & $8,7(36)$ & $(69,5)$ & $(38,0)$ \\
\hline Y & 15 & $6,2(41)$ & $3,8(25)$ & $0,0(0)$ & $5,0(33)$ & $(58,6)$ & $(33,3)$ \\
\hline N & 16 & $4,2(26)$ & $2,8(18)$ & $0,0(0)$ & $9,0(56) *$ & $(73,8) *$ & $(56,2) *$ \\
\hline $\mathrm{L}$ & 28 & $7,3(26)$ & $5,7(20)$ & $2,3(8)$ & $12,7(45)$ & $(65,6)$ & $(53,4)$ \\
\hline G & 28 & $7,0(25)$ & $5,5(20)$ & $2,3(8)$ & $13,2(47)$ & $(66,8)$ & $(55,3)$ \\
\hline$\Lambda$ & 30 & $8,2(27)$ & $4,8(16)$ & $2,0(7)$ & $15,0(50)$ & $(66,3)$ & $(56,6)$ \\
\hline D & 31 & $9,2(30)$ & $5,8(19)$ & $2,8(9)$ & $13,2(43)$ & $(61,2)$ & $(51,9)$ \\
\hline M & 31 & $7,8(25)$ & $4,7(15)$ & $3,0(10)$ & $15,5(50)$ & $(65,1)$ & $(59,6)$ \\
\hline $\mathrm{E}$ & 33 & $9,2(28)$ & $5,3(16)$ & $3,3(10)$ & $15,2(46)$ & $(62,2)$ & $(56,0)$ \\
\hline means & 26,5 & $7,4(29)$ & $4,8(18)$ & $2,0(7)$ & $12,4(46)$ & $(64,9)$ & $(52,7)$ \\
\hline
\end{tabular}

